\title{
Cardiovascular and Neurophysiologic Changes during Graded Duration of Apnea in Piglets
}

\author{
U. M. SANOCKA, D. F. DONNELLY, AND G. G. HADDAD \\ Department of Pediatrics (Neonatal and Pulmonary Divisions), Columbia University, College of Physicians and \\ Surgeons, New York, New York 10032
}

\begin{abstract}
To examine the interrelationship between the duration of apnea and changes in oxygen saturation, blood pressure, electroencephalogram (EEG), and heart rate, reflex apnea of $10,20,40$, and $60 \mathrm{~s}$ duration was induced by stimulating the superior laryngeal nerves. Piglets ( $n=11$, age 5-14 days) were chronically instrumented for continuous monitoring of $\mathrm{SaO}_{2}$ and blood pressure and for sampling arterial blood. Ventilation was recorded using whole body plethysmography and EEG and electrocardiogram were measured by acutely placed subcutaneous electrodes. Central apnea produced an immediate rise in blood pressure and a decrease in $\mathrm{SaO}_{2}$ by $20 \mathrm{~s}$. By $30 \mathrm{~s}$ into the apnea, EEG amplitude had already decreased. Major cardiac slowing did not occur until $80 \mathrm{~s}$ after the start of apnea. Hyperoxia delayed the start of desaturation, hypertension, and EEG attenuation. These data suggest that during superior laryngeal nerve-induced apnea in young piglets: 1) desaturation can reach profound levels rapidly, 2) EEG amplitude decreases substantially and becomes nearly isoelectric within $1 \mathrm{~min}$, and 3) bradycardia is a late manifestation when compared to changes in oxygen saturation, blood pressure, and EEG. (Pediatr Res 23:402407, 1988)
\end{abstract}

\section{Abbreviations}

SLN, superior laryngeal nerves

EEG, electroencephalogram

$\mathrm{SaO}_{2}$, arterial oxygen saturation

MAP, mean arterial blood pressure

EKG, electrocardiogram

IVH, intraventricular hemorrhage

Apnea is a common problem in neonatal intensive care units with an incidence of $80-90 \%$ in infants weighing less than 1000 $\mathrm{g}(1,2)$. The importance of this phenomenon stems from the fact that apnea has been associated with cyanosis, bradycardia, altered neurologic state (3-7), and recently, with decreased cerei-al blood flow (8).

Despite the importance of apnea as a potentially detrimental phenomenon (9), the time of onset and the sequence of physiologic changes associated with apnea are unclear. Some infants require intervention at $10-15 \mathrm{~s}$ into an apnea, whereas some observations suggest that hypotonia and other indications of cerebral dysfunction do not occur until $45 \mathrm{~s}(3,10)$. Similarly, the latency of bradycardia and its relationship to oxygen satura-

Received May 19, 1987; accepted December 11, 1987.

Correspondence Ulana Sanocka, M.D., Department of Pediatrics, Babies Hospital, Room 115, 3959 Broadway, New York, NY 10032.

Supported by HL-33783. DFD is Parker B Francis Fellow. GGH is an Established Investigator of the American Heart Association. tion is variable. Bradycardia may occur early into an apnea, at a time before significant desaturation $(3,11,12)$, but also can occur late in $40 \%$ of protracted apneas (13) or after the onset of EEG supression (14).

The purpose herein was to examine the sequence of neurologic and cardiovascular consequences of graded periods of apnea. Prolonged neonatal apnea can be of variable etiology such as central nervous system immaturity, infection, metabolic disturbances, IVH, airway obstruction, and vagal reflex. For our studies, we used laryngeal stimulation to induce a central apnea secondary to reflex effect. In this way, apnea duration could be controlled by the duration of stimulus presentation and the cause for central apnea was consistent among experimental animals. Experiments were conducted in piglets because they have a similar time course of brain development and cardiovascular control systems as infants. Inasmuch as unterminated respiratory pauses up to $80 \mathrm{~s}$ duration were examined, similar studies on human infants could not ethically be undertaken. We hypothesized that in healthy animals, significant desaturation and neurologic electroencephalographic alterations occur during the course of an apnea and that bradycardia may be a poor indicator of an apneic period.

\section{MATERIALS AND METHODS}

Eleven farm bred newborn piglets were used. The animals were bottle fed pig milk replacer every $4-5 \mathrm{~h}$ for the first five days of life and then allowed to feed ad libitum from a bowl. Environmental temperature was maintained between $30.5-32^{\circ} \mathrm{C}$. Piglets were weighed daily and an increase in weight was noted in all.

Electrode and catheter placement. On day 4-13 of life, surgery was performed under sterile conditions using Halothane anesthesia. A no. 5 Oxymetrix oxygen saturation catheter was inserted into the carotid artery. This allowed us to make continuous recordings of $\mathrm{O}_{2}$ saturation and blood pressure and to take intermittent samples for blood gas analysis. Both SLN were exposed and isolated along their path from larynx to nodose ganglia. The nerves were cut at the entrance to the larynx and placed in individual cuff electrodes that were sutured to the neighboring laryngeal muscles. These electrodes were constructed by sewing a pair of Teflon insulated steel wires (7 strands no. 44 wire, Medwire Corp., Mt. Vernon, NY) circumferentially within silastic tubes and separated by $2 \mathrm{~mm}$. Because the fine wires allowed for a tight closure of the wound, the site of exteriorization could be kept free from infection. The piglets were then allowed to recover for $24 \mathrm{~h}$.

Experiments were performed 1-2 days after surgery at which time piglets were sedated with penobarbital $(20 \mathrm{mg} / \mathrm{kg}$, intraarterially). Pentobarbital was used to suppress periodic breathing that is observed during SLN stimulation in awake, unanesthetized animals (15). Throughout the experimental period the animal was maintained under a light level of anesthesia as assessed by withdrawal from nocioceptive stimuli. 
Physiologic measurements. Respiration was measured using barometric plethysmography $(16,17)$. In brief, the animal is placed in a closed chamber and tidal volume is calculated from pressure changes due to humidification and heating of inspired air. The chamber air is circulated through a scrubbing system to remove expired $\mathrm{CO}_{2}$ and control for humidity. The total volume of the chamber and scrubbing system is 51 liters. Oxygen was added periodically to maintain an $\mathrm{FiO}_{2}$ between 0.19 and 0.22 .

Oxygen saturation and blood pressure were measured continuously through a carotid artery catheter. Heart rate was monitored by inserting pins subcutaneously and attaching these to electrode wires (17). Similarly, pins were inserted subcutaneously over the temporoparietal cortex to measure the electroencephalogram. A hot water bottle was used to maintain the temperature in the box at $32^{\circ} \mathrm{C}$. After the animal was placed in the chamber, which was carefully sealed to avoid any leakage of air, baseline recordings were obtained. The SLN were briefly stimulated (BAK Electronics, Rockville, MD BPG-1/BSI-2 constant current source, $1 \mathrm{~ms}$ duration, $10 \mathrm{~Hz}$ ) at increasing current until central apnea was produced at which time the stimulus was removed and the current intensity noted.

Each study was divided into a control, stimulus, and poststimulus period. After control recordings (three consecutive 10-s intervals immediately before each stimulus period), the SLN were stimulated for $10,20,40$, and $60 \mathrm{~s}$. Data were analyzed for an additional $20 \mathrm{~s}$ into the poststimulus period. Piglets were allowed to recover spontaneously between stimuli, i.e. all physiologic parameters that were being measured returned to baseline before the next stimulus was applied. At the end of the study rectal temperature was measured.

In six piglets, after SLN stimulation in normoxia, the $\mathrm{FiO}_{2}$ was raised to $50-70 \%$ in order to increase $\mathrm{O}_{2}$ stores and delay the arterial oxygen desaturation associated with apnea. Again the SLN were stimulated to induce central apnea for $10,20,40$, and $60 \mathrm{~s}$.

Data acquisition and statistical analysis. All signals were acquired on a PDP 11/03 computer and transferred to a Prime minicomputer for analysis. The respiratory waveform was graphically displayed for accurate marking of the start and end of inspiration. Tidal volume and respiratory frequency were calculated as previously described $(16,17)$.

The EEG was quantified in one of two ways: 1) in six studies the EEG was bandpass filtered at $0.5-25 \mathrm{~Hz}$ and digitized at 50 $\mathrm{Hz}$. The variance of EEG voltage was computed before and during the apnea and was used as an index of EEG amplitude. 2) In the remaining five studies where EEG tape recording was not available, quantification of EEG amplitude was measured by peak-peak polygraph excursion.

Mean and SE of absolute values as well as percent changes from baseline were computed for all variables. To determine whether significant changes occurred at discrete time points in the stimulus period, stimulus values were compared to those in baseline using Student's paired $t$ test with Bonferroni correction for multiple samples (18). Population differences were considered significant if $p$ was less than 0.05 .

\section{RESULTS}

Bilateral electrical stimulation of the SLN induced alterations in respiratory, cardiovascular, and neurophysiologic functions in lightly anesthetized piglets. Data obtained at 10,20, and $40 \mathrm{~s}$ of the 60 -s stimulus period were identical to those values for $10-$, $20-$, and 40-s stimulus trains. Therefore, only the 60-s stimulus periods were analyzed in detail and are presented herein.

Respiratory pattern and function. Immediately after the start of SLN stimulation the piglet became apneic (Fig. 1). Apnea lasted the duration of the stimulus period but with longer stimulation (40 and $60 \mathrm{~s}$ ) it continued after stimulus cessation (Fig. 1). In general, the longer the stimulus period, the longer the time to resumption of spontaneous and regular breathing. The range of the poststimulus apneic period after $60 \mathrm{~s}$ of stimulation was $10-110$ s. Almost simultaneously with the onset of apnea, $\mathrm{O}_{2}$ saturation began to decrease; by $30 \mathrm{~s}$ into the apnea, $\mathrm{SaO}_{2}$ was down to $50 \%$, and by $60 \mathrm{~s}$ it had dropped to $25 \%$ (Table 1). The fall in $\mathrm{O}_{2}$ saturation was significant at $20 \mathrm{~s}$ and continued to be so throughout the entire stimulus and poststimulus period. The mean $\mathrm{PaO}_{2}$ measured at the end of the 60 -s period of stimulation was $25 \mathrm{~mm} \mathrm{Hg}$ and $\mathrm{PaCO}_{2}$ increased from 37 to $50 \mathrm{~mm} \mathrm{Hg}$. The $\mathrm{SaO}_{2}$ was fit to an exponential and estimated as $\mathrm{SaO}_{2}=$ $90 \exp (-0.021 \mathrm{t}) ; r=0.99$.

Cardiovascular function. Blood Pressure. The MAP during baseline recordings was $82 \mathrm{~mm} \mathrm{Hg}$ (Table 1). MAP began to rise approximately $10 \mathrm{~s}$ after the onset of apnea and almost simultaneously with oxygen desaturation (Fig. 2). The piglets became considerably hypertensive. By $30 \mathrm{~s}$ MAP was $110 \mathrm{~mm} \mathrm{Hg}$ and by $60 \mathrm{~s}$ reached a peak of $125 \mathrm{~mm} \mathrm{Hg}$, an increase of $55 \%$. After the start of apnea, all MAP values were significantly elevated above control. Blood pressure gradually fell in the poststimulus period.

Heart Rate. The mean heart rate during the control period was 198 beats/min (Table 1). Ten seconds after the start of stimulation the mean heart rate had decreased to 193 and by 20 $\mathrm{s}$ it was significantly down to 185 . During the rest of the period, although the average heart rate remained below the baseline value, the differences were insignificant. At no time during the $60 \mathrm{~s}$ of apnea was the mean heart rate less than 170 beats $/ \mathrm{min}$. It was not until $80 \mathrm{~s}$ after the start of apnea or $20 \mathrm{~s}$ into the poststimulus period that the heart rate decreased to less than $75 \%$ of control ( 150 beats/min).

Neurophysiologic Function. There was a substantial effect on
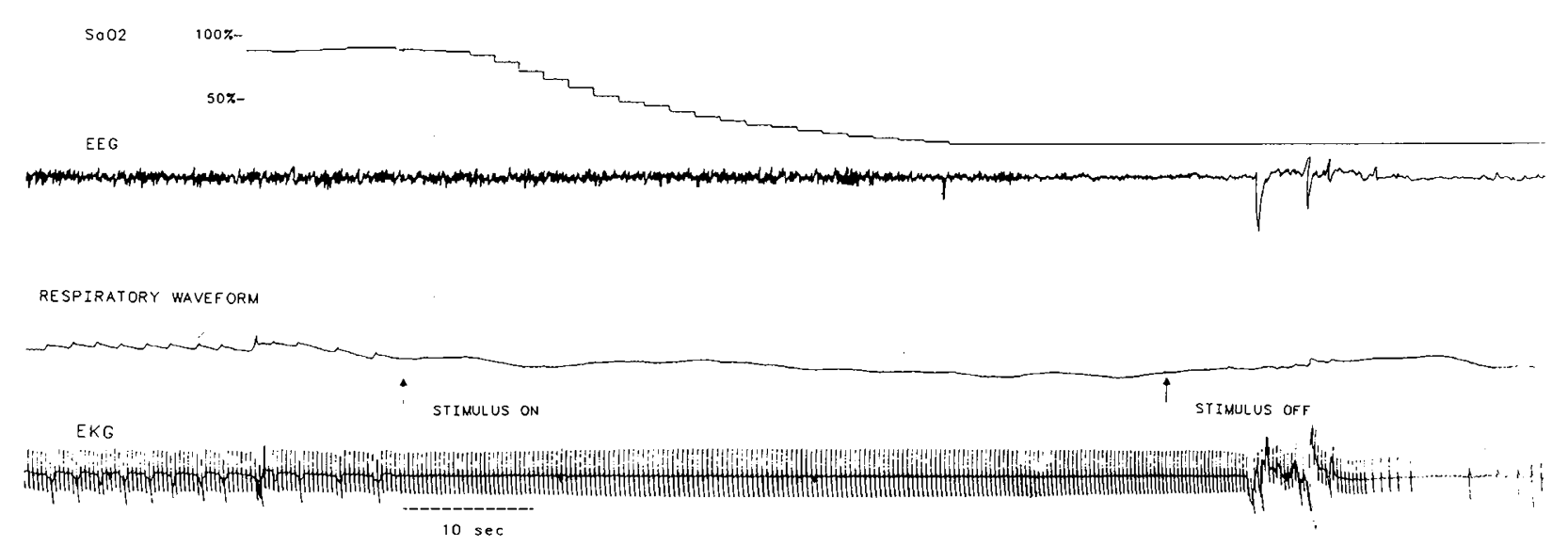

Fig. 1. Original polygraph tracing before (left $)$ and through a 60 -s stimulus period in room air. Signals recorded were arterial oxygen saturation (top), EEG, respiration, and EKG. Note rapid desaturation and a gradual decline of EEG amplitude; bradycardia occurred late in the apnea. 
Table 1. Mean \pm SEM of arterial oxygen saturation, arterial blood pressure, EEG amplitude, and heart rate for control, 60-s stimulus, and 20 -s poststimulus period

\begin{tabular}{|c|c|c|c|c|c|c|c|c|c|}
\hline & \multirow{2}{*}{$\begin{array}{l}\text { Control } \\
\text { period } \\
\text { (s) }\end{array}$} & \multicolumn{6}{|c|}{ Stimulus period (s) } & \multicolumn{2}{|c|}{ Poststimulus period (s) } \\
\hline & & 10 & 20 & 30 & 40 & 50 & 60 & 10 & 20 \\
\hline $\mathrm{SaO}_{2}(\%)(n=11)$ & $85 \pm 3$ & $79 \pm 4$ & $63 \pm 5^{*}$ & $48 \pm 6^{*}$ & $36 \pm 6^{*}$ & $30 \pm 5^{*}$ & $24 \pm 4^{*}$ & $21 \pm 3^{*}$ & $18 \pm 2^{*}$ \\
\hline $\begin{array}{l}\mathrm{BP}(\mathrm{mm} \mathrm{Hg}) \\
\quad(n=12)\end{array}$ & $82 \pm 3$ & $86 \pm 4^{*}$ & $97 \pm 5^{*}$ & $110 \pm 5^{*}$ & $120 \pm 5^{*}$ & $124 \pm 4^{*}$ & $125 \pm 4^{*}$ & $119 \pm 5^{*}$ & $112 \pm 5^{*}$ \\
\hline $\begin{array}{l}\mathrm{EEG}(\times 10 \mathrm{UV}) \\
\quad(n=16)\end{array}$ & $11 \pm 1$ & $11 \pm 1$ & $10 \pm 1$ & $8 \pm 1^{*}$ & $7 \pm 1^{*}$ & $7 \pm 1^{*}$ & $5 \pm 1^{*}$ & $2 \pm 1^{*}$ & $1 \pm 0^{*}$ \\
\hline
\end{tabular}

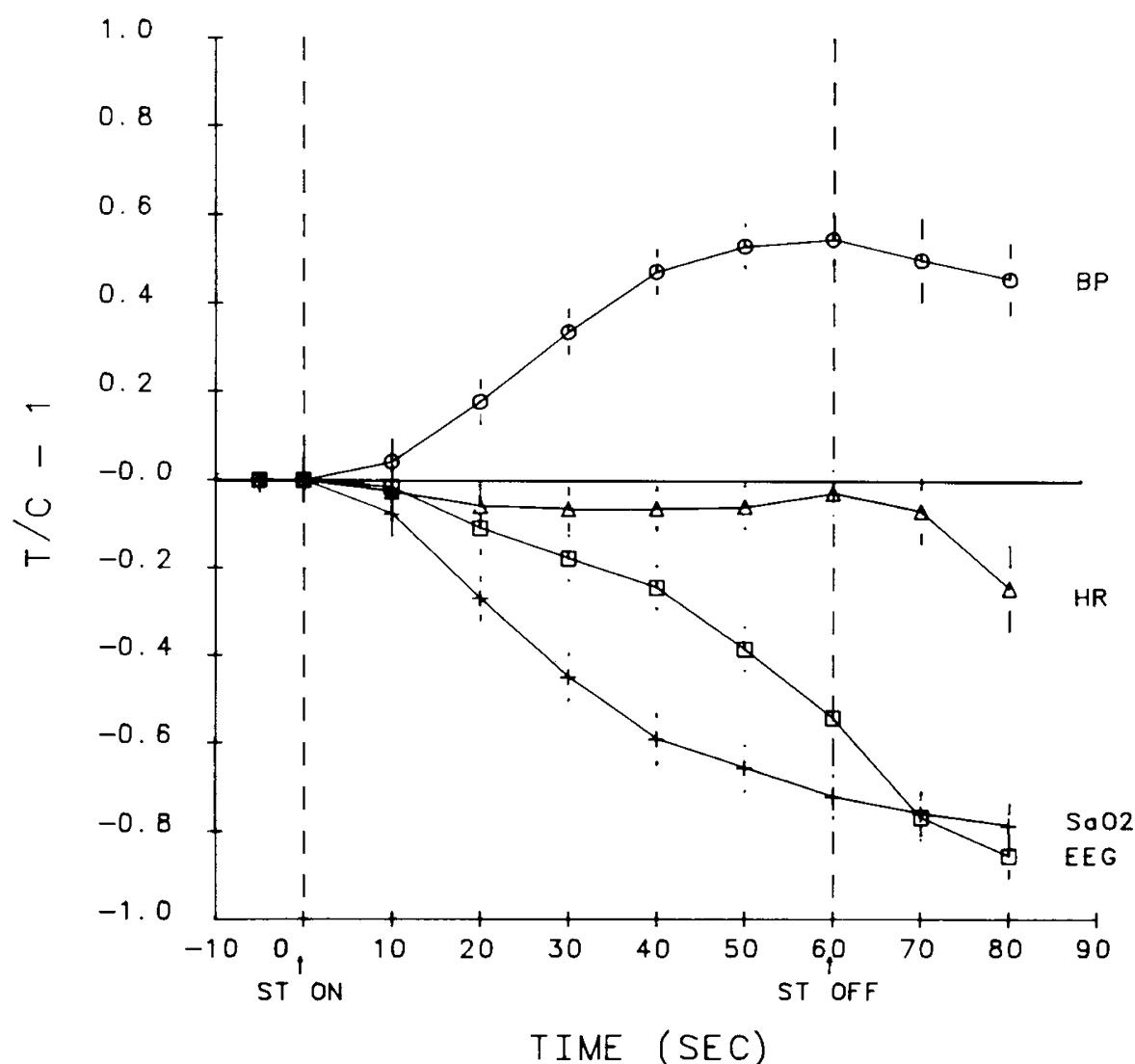

Fig. 2. Percent change from control value (mean $+\mathrm{SEM}$ ) of systemic blood pressure (circle), heart rate (triangle), EEG (square), and arterial oxygen saturation (cross) during $60 \mathrm{~s}$ of SLN-induced apnea and $20 \mathrm{~s}$ of the poststimulus period in room air.

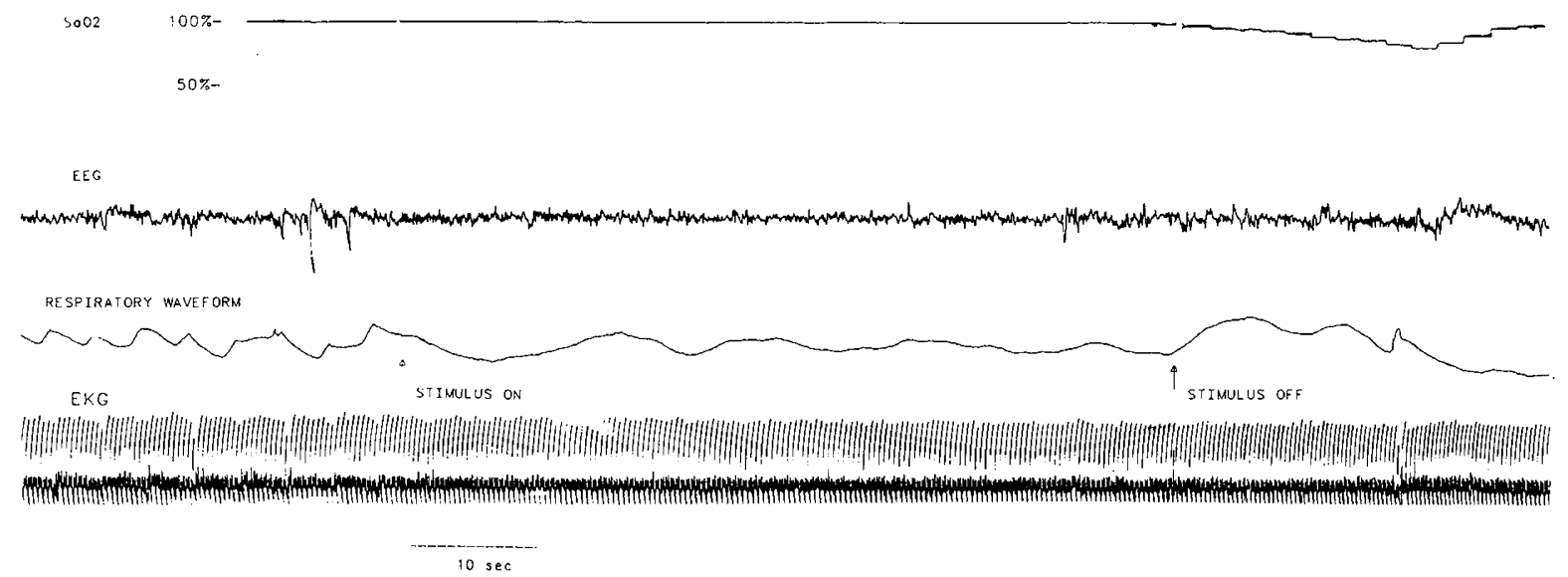

Fig. 3. Original polygraphy tracing before (left) and through a 60 -s stimulus period with $\mathrm{FiO}_{2}=0.6$. Signals recorded were arterial oxygen saturation (top), EEG, respiration, and EKG. Note delayed desaturation and no EEG attenuation or bradycardia. 


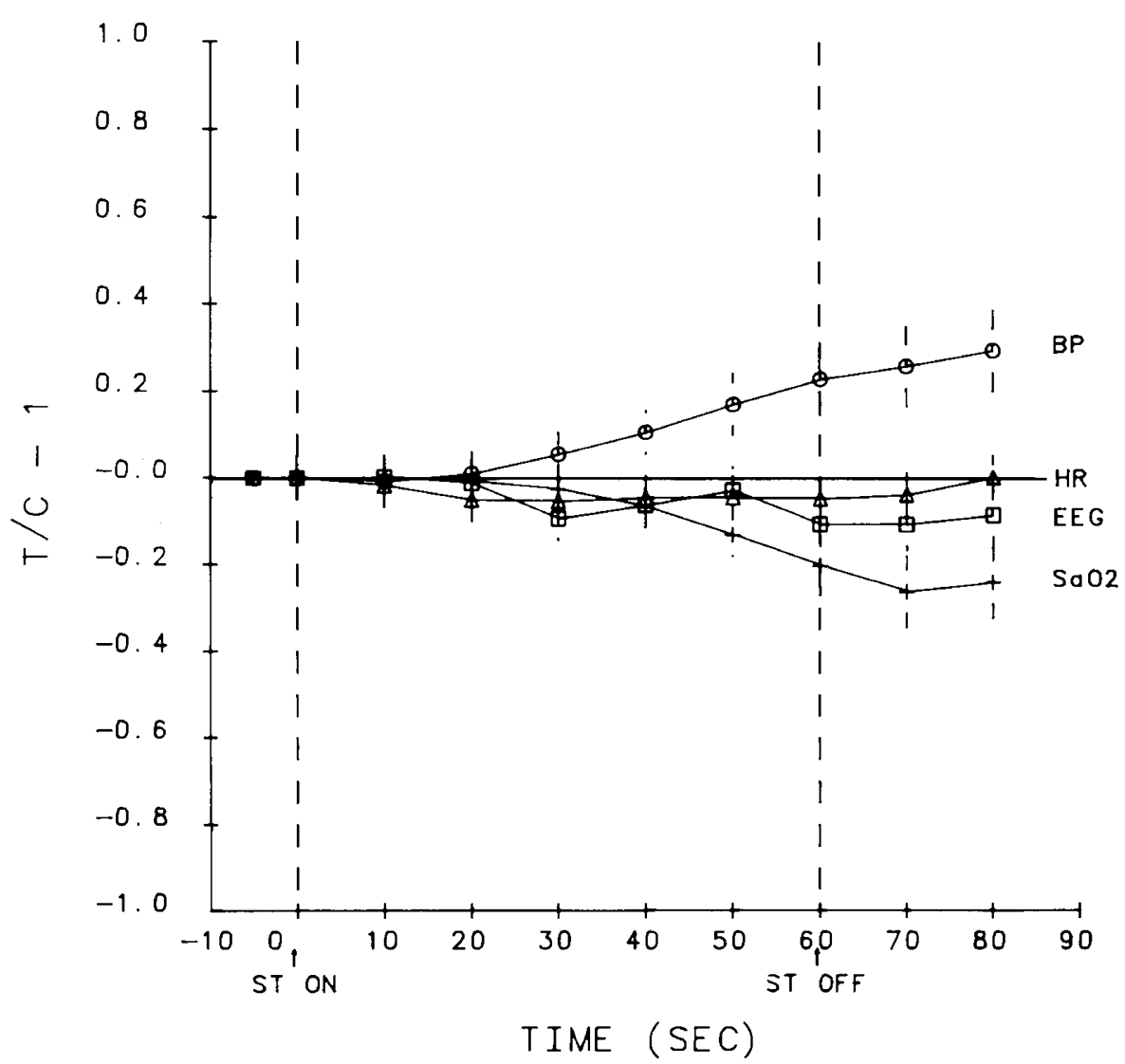

Fig. 4. Percent change from control value (mean + SEM) of systemic blood pressure (circle), heart rate (triangle), EEG (square), and arterial oxygen saturation (cross) during $60 \mathrm{~s}$ of SLN-induced apnea and $20 \mathrm{~s}$ into the poststimulus period in a hyperoxic environment $\left(\mathrm{FiO}^{2}=0.5-0.7\right)$. Note that hyperoxia delayed the start of desaturation and EEG attenuation, bradycardia did not occur.

Table 2. Mean \pm SEM of arterial oxygen saturation, arterial blood pressure, EEG amplitude, and heart rate for control, 60-S stimulus, and 20-s poststimulus period during hyperoxia

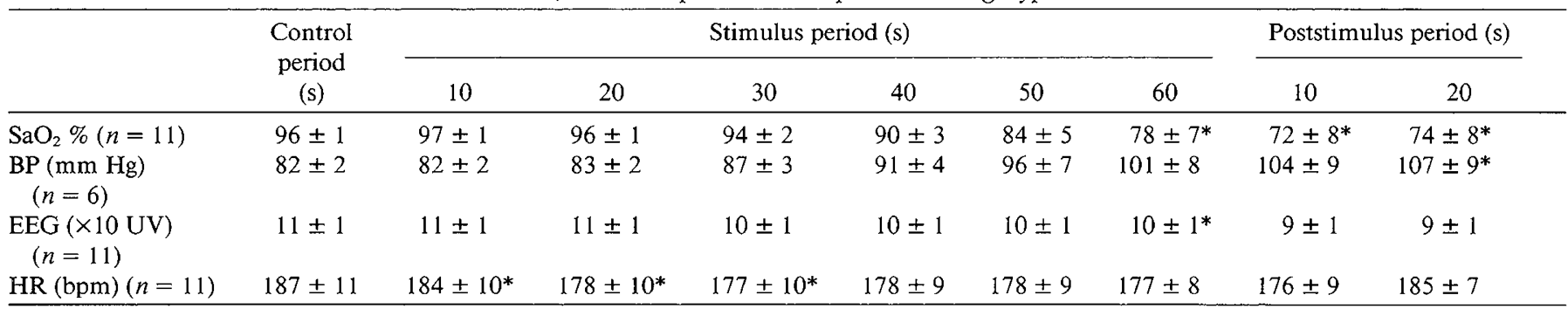

${ }^{*} p<0.05$ versus control.

the EEG as measured by a decrease in amplitude. As seen in Table 1, the EEG amplitude decreased early in the stimulus period, and this decrease was statistically significant by $30 \mathrm{~s}$. At approximately $55 \mathrm{~s}$, the EEG was down to $50 \%$ of baseline and between 60 and $70 \mathrm{~s}$ there was complete flattening in $80 \%$ of the trials (Fig. 2). The EEG amplitude was fit to a single exponential and estimated as EEG $(\%$ control $)=100 \exp (-0.027 \mathrm{t}) ; r=0.89$.

Hyperoxia. The effect of inducing a similar central apnea in a hyperoxic environment is shown in Figure 3. The increased $\mathrm{O}_{2}$ stores delayed the start of desaturation and hypertension; EEG attenuation was mild (10\% of baseline at 60 s) (Fig. 4). Mild cardiac slowing only occurred during the first $30 \mathrm{~s}$ of stimulation (Table 2). Average baseline $\mathrm{PaO}_{2}$ was $217 \mathrm{~mm} \mathrm{Hg}$ and at $60 \mathrm{~s}$ into the stimulus period it was $110 \mathrm{~mm} \mathrm{Hg}$. Mean $\mathrm{PaCO}_{2}$ increased from 35 to $55 \mathrm{~mm} \mathrm{Hg}$ after $60 \mathrm{~s}$ of stimulation.

\section{DISCUSSION}

Respiration in immature infants is characterized by a wide spectrum of breathing patterns ranging from regular breathing, to periodic breathing, to apnea. Apnea can be life-threatening and is usually considered dangerous if longer than $20 \mathrm{~s}$, or if associated with cyanosis, pallor, bradycardia, or hypotonia (19).

In general, there are two ways of monitoring the severity of an apnea: 1) by the duration of the apnea itself, the rationale being that the longer the apneic episode, the more severe the sequelae and 2) by the advent of bradycardia. Both methods have inherent difficulties. Most ICU respiratory transducers are based on thoracic impedance changes. This method is sensitive to chest wall movements and thus insensitive to obstructive or mixed apneas. Criteria for critical apnea durations based on this device may therefore be misleading. Heart rate monitoring may also be used for indicating an apneic event. However, bradycardia of less than 100 beats/min is variably associated with apnea, occurring in only $56 \%$ of apneas lasting between $20-40$ s duration (13).

Developing criteria for critical apneic times is further complicated by the variable etiology of neonatal apnea. Whereas apnea may be related to immaturity of the central nervous system (4, 20 ), it may be also caused by a number of conditions including 
infection, metabolic disturbances, IVH, and vagal stimulation. Furthermore, variability among infants in lung function and resting $\mathrm{PaO}_{2}$ values may alter a critical value in apneic duration among infants.

The purpose herein was to examine the cardiovascular and neurophysiologic changes that occur during graded apneic periods under controlled conditions. Apneas were produced in healthy, young piglets using reflex stimulation, and thus the etiologies for the apneas were the same in all subjects.

Apnea and oxygen desaturation. Herein we have demonstrated that in lightly anesthetized newborn piglets, central apnea led to rapid, progressive desaturation that continued as long as the piglet remained apneic. Oxygen saturation was significantly lower than control by the first $10 \mathrm{~s}$ of apnea. Similar results have been found in preterm infants monitored for both central and obstructive apnea, in whom the mean time to onset of desaturation was $6.9 \mathrm{~s}(21)$. This rapid fall in oxygen saturation can be explained on the basis of a high metabolic oxygen consumption in relation to their lung oxygen stores in young infants. In addition, newborn infants may start at a lower $\mathrm{O}_{2}$ saturation than older infants or adults and thus be on the steep part of the oxyhemoglobin dissociation curve (22).

Apnea and hypertension. Hypertension developed in synchrony with $\mathrm{O}_{2}$ desaturation. The effect of hyperoxia was to delay the start of desaturation and hypertension. At $60 \mathrm{~s}$, mean blood pressure during normoxia and hyperoxia increased by 55 and $23 \%$, respectively (Figs. 2 and 4). Therefore, the hypertensive response seen during SLN-induced central apnea (without periodic breathing) appears secondary to hypoxemia and, to a lesser degree, to the activation of the laryngeal reflex.

Apnea and heart rate. Overall, only mild changes in heart rate occurred during SLN-induced apnea. In the beginning of the respiratory pause, there was a slight but significant decrease in heart rate. This early fall in heart rate has been previously reported during spontaneous respiratory pauses in infants and is believed to be secondary to the absence of lung inflation (23). A drop in heart rate was also seen in newborn lambs in which apnea was elicited by laryngeal water stimulation (24). However, the magnitude of heart rate slowing that we observed is less than that seen in the above, tracheostomized lambs. Although this difference may be due to the use of pentobarbital in our studies (25), we believe it is more likely due to differences in the experimental preparations. In our piglets the upper airway remained intact and thus they could regulate expiratory lung volume. Increases in lung volume are known to dramatically attenuate the bradycardia associated with laryngeal reflex activation (25).

Pentobarbital may have affected the cardiovascular function in our studies. However, existing evidence suggests that its effect on blood pressure and heart rate is small or negligible at the doses used (26). Also, this anesthetic dosage maintains baroreceptor and peripheral vascular constrictor responses (27). From our data, a comparison of the control heart rates and blood pressure against a population of unaesthetized piglets (28) of the same age showed a slight difference in blood pressure (80 versus $82 \mathrm{~mm} \mathrm{Hg})$ and a resting heart rate about $15 \%$ higher $(170$ versus $198 \mathrm{bpm}$ ).

Whether the SLN stimulation per se contributed to the cardiovascular changes cannot be determined with certainty. However, evidence from this laboratory as well as other laboratories suggest that the stimulation did not play a major role. Approximately $80 \%$ of the cardiovascular changes are secondary to the induced apnea, loss of lung inflation reflexes, and blood gas changes (25), i.e. reflexes evoked regardless of the cause of the apnea. Furthermore, we have previously shown that SLN stimulation in unanesthetized piglets resulted in no significant change in heart rate or blood pressure (28). Similarly, herein SLN stimulation in the presence of hyperoxia had a negligible effect on heart rate or blood pressure (Table 2).

Apnea and EEG. Of particular interest was the observation

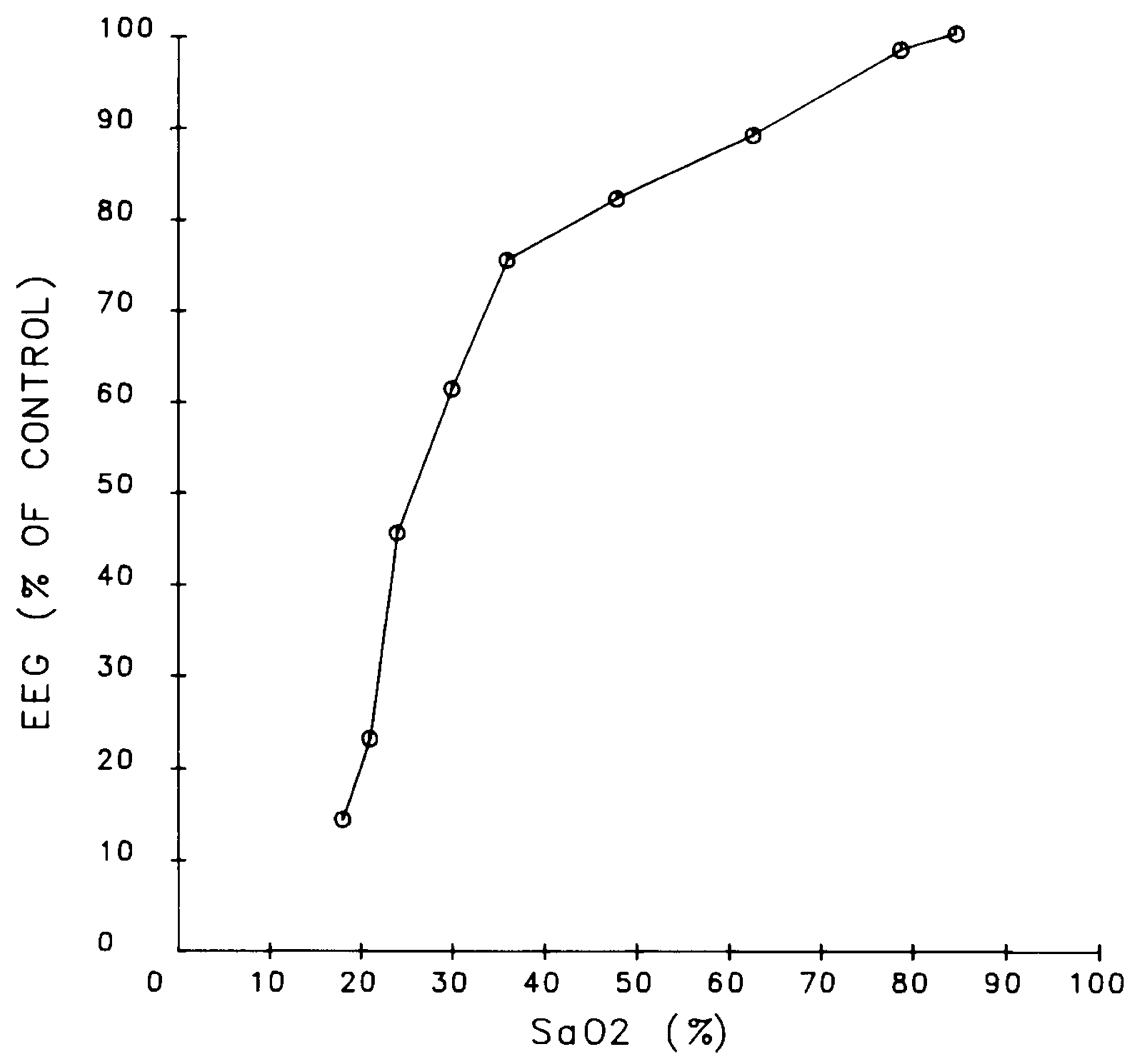

Fig. 5. EEG (percent change from control) versus oxygen saturation. Note rapid decline of EEG amplitude with saturation when the latter falls below $50 \%$. 
that after approximately $30 \mathrm{~s}$ of apnea, EEG amplitude began to decrease and continued to do so until complete electrical inactivity. When piglets were made hyperoxic, desaturation was delayed and there was minimal EEG attenuation (Fig. 4). Thus, EEG activity appears to correlate well with the change in $\mathrm{SaO}_{2}$ (Fig. 5). Although anesthesia may have influenced the sensitivity of the EEG to $\mathrm{SaO}_{2}$ changes, we believe that the anesthetic effect is relatively minor compared to the major changes seen in our animals. Piglets were only lightly anesthetized and low dose barbiturates cause activation rather than attenuation of the EEG (29, 30; Sanocka UM, Donnelly DF, Haddad GG, unpublished observations).

EEG changes have been observed in newborn infants during apneic attacks. In 1969, Roberton (31) noted that during attempts at weaning preterm infants from the respirator they frequently became apneic, hypoxic, and EEG activity decreased and, in some cases, became virtually flat. More recently, Southall et al. (32) described a form of "prolonged expiratory apnea" in infants during which desaturation occurred and EEG amplitude decreased 25-30 s after the onset of apnea. This latency period was similar to that which we observed experimentally.

Clinical implications. Our data herein demonstrate that under certain circumstances, there is a consistent pattern of cardiovascular and neurophysiologic response that we believe is mostly due to the induced apnea and its consequences. Although these observations are made in anesthetized piglets, we suggest that this patterned response may not be very different from that in the newborn suffering from some forms of apneic spells.

The most striking and clinically relevant finding is that the heart rate remained relatively stable despite marked hypoxia and EEG attenuation. Heart rate was more than 120 beats/min when $\mathrm{SaO}_{2}$ was very low (less than $40 \%$ ), and at this time the EEG was nearly isoelectric. Southall et al. (32) previously reported that major bradycardia did not develop in some infants with prolonged expiratory apnea despite desaturation and EEG changes. From our clinical experience, we have seen two infants who developed a flat EEG during apnea. In one of these infants, EEG flattening was noted before the onset of major bradycardia. After stimulation and resumption of spontaneous breathing, the EEG remained flat for $1.5 \mathrm{~min}$ despite a return of the heart rate to 150 beats/min. Subsequently, EEG returned to normal.

What remains to be established is how frequently EEG flattening occurs in association with apneic spells and the exact relationship of this change to the degree of hypoxia, bradycardia, and type of apnea. In addition, little is known of the neurologic sequelae of apnea, not confounded by a variety of other perinatal insults to which the infant is subjected. For instance, in followup studies of low birth weight infants (less than $1500 \mathrm{~g}$ ) without intraventricular hemorrhage, $10 \%$ were found to have major neurodevelopmental handicaps and $40 \%$ had minor handicaps (33). Perhaps repeated episodes of clinically undetected hypoxemia, severe enough to lead to EEG changes, contributed to this handicap.

In conclusion, we have shown that in newborn piglets SLNinduced central apnea results in rapid desaturation and hypertension followed by EEG flattening. A modest decrease in heart rate occurs late, after the EEG has become nearly flat. Although these observations were made in anesthetized and instrumented piglets, they may have important implications in the care of newborn infants. Our clinical experience together with data presented by Southall et al. (32) have suggested that the same sequence of events may occur in some types of infantile apneas. Inasmuch as bradycardia can be a late manifestation of hypoxemia, it may not be appropriate to rely solely on standard apnea and heart rate monitors. Our experimental data suggest that infants should have continuous $\mathrm{tcPO}_{2}$ or arterial pulse oximetry recorded for proper assessment of cardiopulmonary function. This will allow for earlier intervention by health care personnel and may prevent potentially deleterious effect of hypoxemia on the central nervous system.
Acknowledgments. The authors are grateful to Dr. L. Stanley James and Dr. Robert B. Mellins for critically reviewing this manuscript.

\section{REFERENCES}

1. Alden ER, Mandelkorn T, Woodrum DE 1972 Morbidity and mortality of infants weighing less than 1000 grams in an intensive care nursery. Pediatrics 50:40-49

2. Tudehope DI, Rogers Y 1984 Clinical spectrum of neonatal apnoea in very low birthweight infants. Aust Paediatr $\mathrm{J}$ 20:131-135

3. Daily W, Klaus M, Belton H, Meyer P 1969 Apnea in premature infants: monitoring, incidence, heart rate changes, and an effect of environmental temperature. Pediatrics 43:510-518

4. Girling DJ 1972 Changes in heart rate blood pressure and pulse pressure during apneic attacks in newborn babies. Arch Dis Child 47:405-410

5. Kahn A, Blum D, Waterschoot P, Engelman E, Smets P 1982 Effects of obstructive sleep apneas on transcutaneous oxygen pressure in control infants siblings of sudden infant death syndrome victims and near miss infants: comparison with the effect of central sleep apneas. Pediatrics 70:852-857

6. Peabody JL, Gregory GA, Willis MM, Philip A, Lucey JF 1979 Failure of conventional monitoring to detect apnea resulting in hypoxemia. Birth Defects 15:275-284

7. Storrs CN 1977 Cardiovascular effects of apnoea in preterm infants. Arch Dis Child 52:534-540

8. Perlman JM, Volpe JJ 1985 Episodes of apnea and bradycardia in the preterm newborn: impact on cerebral circulation. Pediatrics 76:333-338

9. McDonald A 1963 Cerebral palsy in children of very low birth weight. Arch Dis Child 38:579-587

10. Avery GB 1987 Neurologic disorders. In: Neonatology: Pathology and Management of the Newborn. JB Lippincott Co, Philadelphia, pp 1083-1085

11. Haddad GG, Jeng HJ, Lai TL 1987 Heart rate variability during respiratory pauses in puppies in dogs. Pediatr Res 22:306-311

12. Vyas H, Milner AD, Hopkin IE 1981 Relationship between apnoea and bradycardia in preterm infants. Acta Paediatr Scand 70:785-790

3. Gabriel M, Albani M 1976 Cardiac slowing and respiratory arrest in preterm infants. Eur J Pediatr 122:257-261

14. Duell RK 1973 Polygraphic monitoring of apneic spells. Arch Neurol 28:7176

15. Donnelly DF, Haddad GG 1986 Effect of graded anesthesia on laryngealinduced central apnea. Respir Physiol 66:235-245

16. Epstein RA, Epstein MAF, Haddad GG, Mellins RB 1980 Practical implementation of the barometric method for measurement of tidal volume. J Appl Physiol 49:1107-1115

17. Haddad GG, Gandhi MR, Mellins RB 1982 Maturation of ventilatory response to hypoxia in puppies during sleep. J Appl Physiol 52:309-314

18. Glantz SA 1981 The special case of two groups: the $t$ test. In: Glantz SA (ed) Primer of Biostatistics. McGraw Hill, New York, pp 87-92

19. Nelson NM and Members of Task Force on Prolonged Apnea 1978 Report of the task force on prolonged apnea of the American Academy of Pediatrics. Pediatrics 61:651-652

20. Henderson-Smart DJ 1981 The effect of gestational age on the incidence and duration of recurrent apnoea in newborn babies. Aust Paediatr J 17:273276

21. Henderson-Smart DJ, Butcher-Puech MC, Edwards DA 1986 Incidence and mechanism of bradycardia during apnoea in preterm infants. Arch Dis Child 61:227-232

22. Henderson-Smart DJ 1980 Vulnerability to hypoxemia in the newborn. Sleep 3:331-342

23. Haddad GG, Bazzy AL, Chang SL, Mellins RB 1984 Heart rate pattern during respiratory pauses in normal infants during sleep. $\mathrm{J}$ Dev Physiol 6:329-337

24. Marchal F, Corke BC, Sundell H 1982 Reflex apnea from laryngeal chemostimulation in the sleeping premature newborn lamb. Pediatr Res 16:621627

25. Grogaard J, Lindstrom DP, Stahlman MT, Marchal F, Sundell H 1982 The cardiovascular response to laryngeal water administration in young lambs. $\mathrm{J}$ Dev Physiol 5:353-370

26. Bailie MD, Alward CT, Sawyer DC, Hook JB 1979 Effect of anesthesia on cardiovascular and renal function in the newborn piglet. J Pharmacol Exp Ther 208:298-302

27. Buckley N, Brazeau P, Frasier ID 1986 Intestinal and femoral blood flow autoregulation in developing swine. Biol Neonate 49:229-240

28. Donnelly DF, Haddad GG 1986 Respiratory changes induced by prolonged laryngeal stimulation in awake piglets. J Appl Physiol 61:1018-1024

29. Pichlmayr I, Lips U, Kunkel H 1984 Intravenous anesthetics. In: The Electroencephalogram in Anesthesia. Springer-Verlag, New York, pp 90-110

30. Shapiro HM 1986 Anesthesia effects upon cerebral blood flow cerebral metabolism and the electroencephalogram. In: Miller RD (ed) Anesthesia, 2nd ed. Churchill-Livingstone, New York, pp 1249-1288

31. Roberton NRC 1969 Effect of acute hypoxia on blood pressure and electroencephalogram of newborn babies. Arch Dis Child 44:719-725

32. Southall DP, Johnson P, Salmons S, Tolbert DG, Helms PJ 1985 Prolonged expiratory apnoea: a disorder resulting in episodes of severe arterial hypoxaemia in infants and young children. Lancet 2:571-577

33. Papile LA, Munsick-Bruno G, Schaefer RN 1983 Relationship of cerebral intraventricular hemorrhage and early childhood neurologic handicaps. $J$ Pediatr 103:273-277 